\title{
A cidade representada: as ruas da cidade e a memória republicana em Campinas
}

Américo Baptista Villela *

\section{Resumo}

No presente ensaio analisa-se um aspecto da construção da memória da cidade de Campinas e procura-se demonstrar que a construção da identidade campineira com o movimento abolicionista e republicano oculta o debate travado entre esses e os escravistas e ou monarquistas, e a realidade complexa em que ocorre. Recuperar o debate por meio da análise dos anais da Câmara de Vereadores e das leis que nomeiam as ruas da cidade é o que foi realizado. Na reconstituição do mesmo demonstra-se que a associação entre republicanos e abolicionistas como sinônimos, ou o inverso, monarquistas como escravistas, não resiste a uma análise mais profunda das fontes pois há republicanos escravistas, bem como monarquistas abolicionistas.

Palavras-chave: Campinas. Memória. República

Representations of the city: the street of the city and the republican memory in Campinas

\begin{abstract}
In this assay we analyze one of the aspects of the construction of memory from Campinas city. This analysis aims to show that the construction of Campinas identity, which refers to abolitionism and republican movement, occults the debate delayed between these and the slaveries and or monarchists and the complex reality where it operates. The recovery of this debate, through the analysis of annals of the towncouncil and the laws that nominate the streets of the city, was accomplished. In this reconstitution it is demonstrated that the association between republicans and abolitionists as synonymous or on the contrary, monarchists as slaveries, there is no deeper analysis of the sources, since there republican slaveries as well abolitionism monarchists.
\end{abstract}

Key-words: Campinas. Memory. Republic. 


\section{A construção da memória pelas ruas da cidade}

Um livro pode fugir da censura dominante, um edifício jamais.

Pode-se evitar a leitura de vários livros, não se pode evitar a leitura continua das casas e das ruas da cidade. (GUIDUCCI, 1980, p. 12).

A cidade representa, simbolicamente, a vida associada inteira dos homens, suas relações, suas contradições, suas tensões; no entanto, muitas vezes (seria melhor quase sempre) a leitura proposta e aceita desta cidade tende a obscurecer essas contradições e tensões, construindo uma representação de homogeneidade e progresso tecnológico. Isto ocorre de diversas formas: uma delas, talvez a principal, é por meio da produção de uma memória histórica que sacraliza seus documentos, monumentos, edifícios, nomes de ruas e logradouros; enfim, de vestígios de um passado elevados à condição de patrimônio histórico e cultural de uma dada coletividade e, nesse processo, são "silenciadas" as próprias contradições que eles encerram em si e o porquê desses objetos ou nomes terem sido os escolhidos para comporem esse patrimônio.

Assim, no caso de Campinas, ao observarmos o túnel de pedestres da Estação da Cia. Paulista de Estradas de Ferro, inaugurado em 1918, e que une o Centro à Vila Industrial, percebemos uma obra de arquitetura e, por "esquecermos" o contexto social de sua época de produção, não conseguimos notar que esta obra é a resposta de uma sociedade que rapidamente viu sua vocação industrial despertar e se desenvolver. Tal desenvolvimento se deu segregando espaços, transformando a terra em uma mercadoria cada vez mais valiosa e no qual a expulsão da classe trabalhadora para os "arrabaldes" é imperiosa (SANTOS, 2002). Isto porque, se por um lado os trabalhadores são percebidos como necessários à produção material da sobrevivência da sociedade, por outro representam uma ameaça aos padrões civilizatórios desejados pela elite dominante em virtude de seus "maus hábitos, como cuspir no chão, ser promiscuo e a constante embriaguez". Além disso, ao demarcarmos espaços na cidade, estabelecemos novos laços de sociabilidade entre os indivíduos e os grupos, ao mesmo tempo em que definimos padrões e 
comportamentos socialmente aceitos e tidos como naturais em cada uma das áreas (MONTEIRO, 2002, p. 24-43).

Se, ao definirmos alguns prédios ou monumentos para preservá-los estamos construindo uma memória, também ao escolhermos determinados nomes para as ruas ou logradouros estamos contribuindo para a produção dessa memória histórica que responde a uma determinada conjuntura política. Analisemos, então, o caso da atual Rua Lusitana. Durante o século 19, mais precisamente até junho de 1871, esta rua era chamada Rua de Baixo, denominação que não agradava aos moradores. Segundo Geraldo Sesso Júnior (1970, p. 347): "Os munícipes não eram muito exigentes; estavam conformados com o estado lastimável de sua rua, mas gostariam de que a mesma tivesse outro nome e não a denominação grotesca de "Rua de Baixo".

Como a Câmara Municipal não tomasse providências para viabilizar a mudança de nome, os próprios moradores,

Depois de uma rápida reunião, tomaram a iniciativa e assim, pela manhã de um dia do mês de junho de 1871, quando algumas pessoas por ali transitavam, foram surpreendidas com tabuletas, colocadas nos cantos das esquinas, em que se lia; "rua do Ouvidor". (SESSO JúNIOR, 1970, p. 347).

A situação produziu protestos da Câmara de Vereadores, os quais exigiram a retirada das tabuletas, o que foi feito contra a vontade de seus moradores. Em 11 de dezembro de 1871, a Câmara resolveu que aquela rua se chamaria Lusitana, tendo em vista a grande concentração de comerciantes portugueses na mesma, denominação que perdurou até 1893, quando houve uma revolta na qual os edis de Campinas acreditaram existir a participação expressiva dos portugueses contra a recém instalada república, o que fez com que a Câmara de Campinas substituísse o nome Lusitana por General Carneiro em homenagem ao oficial morto em combate (SESSO JÚNIOR, 1970, p. 349) (1) para, posteriormente, em 10 de julho de 1922, voltar à denominação de Lusitana. Dessa forma, podemos concluir que, no contexto da crise, era preciso renomear as ruas, reescrevendo a história e apagando da memória as presenças não desejadas; assim como, em situação de normalidade, 
era preciso escrever uma história e construir uma memória que atendesse aos anseios da elite dominante que se manifestava por intermédio da Câmara Municipal.

Nesse sentido é que vemos as ruas que compõem a atual região Central de Campinas serem gradativamente rebatizadas, construindo-se uma nova representação da cidade, a partir da segunda metade do século 19. Nesse momento, é preciso relembrar Júlio Mariano, para quem:

Até $\mathrm{o}$ ano de 1864, a nomenclatura das praças e ruas na 'Princesa do Oeste' tinha um cunho popular. Quando não a devoção religiosa, era o pitoresco que predominava nas placas das vias públicas, que acabavam sendo oficializadas pela Municipalidade. Cada templo católico, como a Matriz Velha, a Matriz Nova e a Igreja do Rosário, patrocinava uma rua. Por vezes, adotavam-se nomes de santos, como São Carlos, São José, São Pedro e o Bom Jesus. Campinas deve ao Dr. Ricardo Gumbleton Daunt o uso das legendas de homenagem cívica ou patriótica nas placas de rua. E afirmamos, desde logo, que data de pouco mais de um século a apresentação à Câmara da primeira proposição cultuando nas vias públicas a memória dos antepassados ilustres. (MARIANO, 1970, p. 115).

A necessidade de se cultuar esta memória é um dos sintomas de uma cidade em transformação e que, no entendimento dos "homens bons", perdia as suas referências históricas sendo, portanto, necessário marcá-las; mas, o que ou quem era considerado ilustre também oscilava com o tempo e as diferentes conjunturas sociais e econômicas vivenciadas pela sociedade e pelas forças políticas que a dirigiam.

Esta mudança ocorre simultaneamente ao processo de aceleração da urbanização da cidade marcada pelo estabelecimento de diversos empreendimentos industriais, bancários, de lazer, colégios, estradas de ferro, e pelo crescimento dos serviços públicos; todos procedentes da diversificação de investimentos do capital cafeeiro e do aumento do fluxo de imigrantes, o que acarretou, como conseqüência, um crescimento da população: de 7.369 habitantes em 1822, passou a ser 33.000 em 1872. Tal crescimento produziu uma vida urbana dependente do capital cafeeiro e gerou, em um futuro próximo, a formação das classes médias - composta pelos profissionais liberais e pequenos comerciantes - e o início de uma classe operária que, gradativamente, construiu uma vida urbana com novos agentes políticos, entre 
os quais merece destaque, no momento em questão, o Partido Republicano Paulista (CARPINTERO, 1996, p. 31-33; BATISTONI, 1996, p. 31-52).

É a modernidade a que Campinas aspira. Modernidade aqui entendida como a definida pelo professor José Roberto do Amaral Lapa:

[...] grosso modo em correspondência com aquela racionalidade burguesa que se estende pelo econômico, pelo social, pelo político e pelo cultural, atingindo as mentalidades, os costumes e a criação estética, não necessariamente nesta ordem [...]. (LAPA, 1996, p. 19).

A modernidade supracitada é resultado das inovações geradas no bojo da Revolução Industrial e das aspirações por ela criadas, o que mantém uma relação antinômica com um determinado passado, que em Campinas serviu para excluir da memória qualquer indício de um passado monarquista ou colonial.

Para Antonio da Costa Santos, não eram apenas os nomes das ruas que mudavam, mas também era preciso transformar fisicamente a cidade. Para isso:

a lei menor da Câmara Municipal, através de seus códigos de posturas urbanas, foi letra em mãos interessadas na construção empírica de uma planta geral desta cidade, cada vez mais apagada de sua evolução histórica anterior e, mesmo do desenho original da freguesia. (SANTOS, 2002, p. 159). (2)

Dessa forma, tornam-se mais facilmente compreensíveis as intervenções no Beco do Caracol para torná-lo "mais organizado e alinhado" dando origem à atual Avenida Benjamin Constant, bem como à substituição dos termos "beco ou travessa", por rua, ou mesmo avenida, assim como "Largo" por Praça. (3) Nesse momento, Campinas se quis perceber moderna, secular, abolicionista e republicana; e, por isso, se fez necessário mudar as suas referências coloniais e imperiais construindose novas referências que estavam de acordo com essa nova forma pela qual a cidade se percebe e se quer fazer representar.

Observemos a tabela abaixo composta com algumas das ruas e logradouros da região do antigo rocio do município: 


\begin{tabular}{|c|c|}
\hline \multicolumn{2}{|c|}{ Tabela Demonstrativa da Oscilação dos Nomes das Ruas da Cidade de Campinas (4) } \\
\hline Período Pré-republicano & Período Republicano (5) \\
\hline Santo Antônio - Bom Jesus & Campos Sales \\
\hline São José & Treze de Maio \\
\hline Casinhas & General Osório \\
\hline Beco do Caracol & Benjamin Constant \\
\hline Rua Alegre & Culto à Ciência - Senador Saraiva \\
\hline Rua do Picador - Rua do Imperador & Marechal Deodoro \\
\hline Rosário & Francisco Glicério \\
\hline Rua da Ponte & Major Sólon \\
\hline Rua Deserta & Álvares Machado \\
\hline Rua São João & Saldanha Marinho \\
\hline Rua do Matadouro & Bernardino de Campos \\
\hline Rua da Cadeia & Largo São Benedito/ Atual Praça Silvia S. Magro \\
\hline Tabela Demonstrativa da Oscilação dos Nomes dos logradouros de Campinas \\
\hline Praça D. Pedro II & Praça 15 de Novembro \\
\hline Campinho dos Pousos, Largo da Forca, Largo & \\
\hline Santa Cruz & \\
\hline
\end{tabular}

A partir da análise da tabela, podemos perceber que as referências à religiosidade e à monarquia são substituídas pelas referências aos líderes republicanos e aos seus ideais, o que se torna mais revelador, se considerarmos que uma das medidas do recém instalado regime republicano estabelece a separação entre o Estado e a Igreja Católica.

Nesse trabalho, procuramos analisar como os vereadores de Campinas justificaram essas mudanças no período compreendido entre 1864 e trinta de novembro de 1892, quando foi adotada a Resolução 57, que estabelecia o seguinte:

Fica deliberado, uma vez para sempre acabar com o systema de alterações dos nomes de ruas, nomes referentes a cidadãos, por isso que á medida que se pretende elevar uns deprimem-se outros, quando todos são egualmente filhos da mesma pátria e quiçá bem intencionados. (6)

Esta resolução foi provocada pelo grande número de mudanças de nomes de ruas e logradouros em uma cidade que se expandia territorialmente, dificultando a localização das pessoas, ao mesmo tempo em que engendrava uma nova memória da cidade, dando-se destaques a alguns personagens, fatalmente os republicanos que rebatizaram duas das principais avenidas da cidade com o nome de seus dirigentes, a saber: as atuais avenidas Campos Sales e Francisco Glicério, e 
deprimindo-se outros, aqueles ligados ao atraso colonial e à monarquia, como $\mathrm{O}$ Largo Santa Cruz, que passou a ser Praça 15 de Novembro, ou a Rua do Imperador, que se tornou Marechal Deodoro. (7)

A Resolução 57 foi revogada pela Lei 87 , datada de 10 de março de 1902, que regulamentou o modo de denominar as ruas e praças. Lei que, em seu artigo $3^{\circ}$, volta a permitir a mudança de nomes das ruas mas, no parágrafo único do mesmo artigo, determina que a alteração deverá contar com a aprovação de dois terços dos vereadores presentes à sessão. Em seu artigo 5ㅜ, a lei estabelece que a própria câmara poderá dar "às vias públicas o nome que lhe parecer mais apropriado, devendo quando for rasoável (sic), respeitar os nomes dados pela tradição, ou pelas gerações passadas às diferentes ruas e praças".

Ao mesmo tempo, no artigo $8^{\circ}$ recomenda

que se escolham de preferência nomes de vultos eminentes, ou fatos da história pátria, ou da humanidade, nomes de beneméritos da própria urbs ou do Estado, já extintos e cuja vida ofereça exemplo de honra, civismo e benemerência.

Já o artigo 09 permite que ruas e praças ostentem "o nome de individualidades vivas ou existentes, uma vez que tenham assignalados serviços à causa pública ou ao município." (8)

A presente lei, muito embora esteja fora do período ao qual nos detemos, é importante para se compreender a alteração dos nomes, pois sinaliza a necessidade dos republicanos de inverter a lógica precedente, pois não era razoável que ruas fossem chamadas de becos; que se mantivessem os nomes da Monarquia retrógrada, porquanto os grandes homens, exemplos de honra, civismo e benemerência agora eram os partidários da república e do liberalismo.

\section{Campinas: Meca Republicana?}

Assim como o Maometano tinham o costume de fazer uma peregrinação a Meca para pedir inspiração a seu Profeta, assim também deviam os republicanos vir a Campinas, não para pedir inspiração aos seus correligionários, mas para ver como germina e como desenvolvê- 
se aqui, graças a um trabalho incessante, a doutrina regeneradora que ainda há de ser a salvação da nossa pátria. (Quintino Bocaiúva apud MENEZES, 1974, p. 38).

O primeiro projeto apresentado pelo vereador Ricardo Gumbleton Daunt para dar nome a uma rua defende o que se segue:

Que em comemoração dos benefícios que esta povoação é devedora a seu fundador Francisco Barreto Leme, e para perpetuar a memória do mesmo, se dê à primeira rua nova que se formar, em virtude do reconhecimento pelos poderes competentes do pleno domínio da Câmara no terreno do seu rocio o nome de 'Rua do Barreto Leme', quando não se queira antes dar este apelido à rua presentemente chamada de 'Matriz Velha'.(MARIANO, 1970, p. 116)

Da análise dessa defesa podemos concluir que, segundo o seu autor, a cidade deve, por intermédio dos nomes de suas ruas, cultuar a memória daqueles que a beneficiaram, mesmo que para isso se apaguem referências anteriores e populares. Não foi esse o parecer da comissão competente da Câmara, ao avaliar o referido projeto. O parecer determinava "Que se dê esta denominação à primeira rua que se fizer, visto que não acha conveniente mudar-se o nome da Rua da Matriz Velha, por já estar muito conhecida com aquele nome." (MARIANO, 1970, p. 116).

Ou seja, era preciso homenagear o fundador, porém não era viável se alterar o nome de uma rua já conhecida, pois isso dificultaria o processo de reconhecimento e localização na cidade pelos seus habitantes e visitantes. Essa situação explica-se pela conjuntura de urbanização acelerada da cidade, já descrita anteriormente, que motivou os vereadores a se manifestarem contra as alterações dos nomes de ruas e logradouros, as quais dificultavam a identificação e localização das pessoas dentro da malha urbana que se projetava, mas este parecer acabou sendo abandonado, como veremos adiante.

Em 1871, duas novas indicações do Dr. Ricardo extraídas das atas da Câmara Municipal de Campinas. A primeira:

que em homenagem ao alto mérito cívico do ilustre paulista o Regente Feijó e em memória de haver sido ele residente neste município durante muitos anos se dê à rua que hoje se 
chama de matriz Nova, em qual ele por algum tempo residia a designação de "Rua do Regente Feijó" devendo o procurador da Câmara mandar colocar nas esquinas onde convier a nova designação desta rua. Fundamentada pelo autor a conveniência da adoção da indicação, foi aprovada. (9)

E a segunda que:

considerando os muitos anos durante os quais era conhecida com o nome de rua do Picador aquela que teve este nome por nela habitarem, e ter a um lado da rua no quarteirão de Ana Corsa (que nesse lado possuía de esquina a esquina) o paulista Salvador de Cerqueira, que como a nobreza paulistana de seu tempo houve um grande apreço a cavalos e ginetes e era destro em arrendá-las e que este nome recorda costumes provinciais, esta Câmara reconsiderando o parecer de uma comissão a cerca de nomenclatura de ruas desta cidade que aqui foi presente e discutido no ano de 1844 (a data correta é 1848), por cuja ocasião este nome foi mudado por uma emenda ao dito parecer contra a opinião dos membros da comissão durante a restauração do antigo nome. Posta em votação esta indicação não foi aprovada. (10)

Nos levam a concluir que, neste período de sua ação política, o vereador estava preocupado em produzir registros da história do município, que estariam sendo esquecidos. O resultado da votação destas duas indicações nos permite pensar que a aprovação à primeira se justifica em virtude da própria história política do Regente Feijó - e obviamente do apoio dos vereadores liberais e republicanos que essa história angariava. O Regente havia participado ativamente do levante liberal paulista em 1842. O levante, em Campinas, resultou na Batalha da Venda Grande, quando os revoltosos foram atacados e apaziguados pelas forças leais ao Imperador. Já a segunda indicação resgatava um velho hábito e uma própria característica da cidade colonial que, neste momento, era substituída pela nova cidade industrial e moderna que se queria projetar.

A preocupação do Dr. Ricardo é nítida em resgatar acontecimentos do passado, e isso se torna mais claro quando observamos a sua conduta e opção política. Sobre o vereador Ricardo Gumblenton Daunt, nos foi informado pelo seu neto, na Monografia Histórica do Município de Campinas: "As lides políticas atraíam-no, escolhendo o partido que mais se coadunava com os seus princípios - o Conservador (....)." (DAUNT NETO, 1952, p. 290). 
E, como tal, suas propostas de homenagens vinculavam-se a personalidades já mortas e às quais a cidade, na sua concepção, era devedora; portanto, ele pretendia perpetuar uma dada leitura da história, bem como resgatar costumes e tradições antigas como as representadas no termo Picador - pessoa que ensina equitação ou amestra cavalos. Nesse sentido, é preciso lembrar que a substituição do nome Picador por Imperador foi aprovada em 04 de outubro de 1848 (11) para marcar a visita do Imperador Pedro II à Campinas, e foi a forma encontrada pela Câmara Municipal de homenagear o ilustre visitante.

Para os republicanos, por outro lado, era preciso reescrever essa história, principalmente após o surgimento e fortalecimento do partido, criando novos personagens e novas histórias, daí a proposta do vereador Correa Dias em se homenagear "Saldanha Marinho" (12), "Álvares Machado" (13) e o "Visconde do Rio Branco" (14) como símbolos da nova era, rebatizando respectivamente as ruas do Matadouro, Rua Deserta e São João. (15) O primeiro era o Presidente da Província de São Paulo, por ocasião da fundação da Cia. Paulista de Estradas de Ferro, e foi quem criou as condições para que a mesma chegasse à cidade de Campinas em 11 de agosto de 1872. (16) O segundo havia se engajado nas causas da Independência e, na Regência, havia se aliado aos Liberais. O terceiro havia sido o chefe do gabinete que aprovou a Lei do Ventre Livre e, por isso, a mesma ficou conhecida com o seu nome. Dessa forma, ao rebatizar as ruas se constrói uma nova imagem da cidade. Imagem que foi sendo construída simultaneamente ao fortalecimento do PRP na Câmara de Vereadores, mas que não ocorreu sem a resistência dos setores conservadores, escravistas e monarquistas da sociedade campineira.

Estes setores se pronunciaram severamente durante o evento da Abolição da Escravidão que acarretou a mudança do nome da Rua de São José para Rua Treze de Maio, como podemos ver. Em primeiro lugar, o vereador José Paulino, uma das lideranças abolicionistas, indica que a sessão de 14 de maio se torne extraordinária e que se mantenha permanente até o povo e a comissão de festejos serem informados da Lei Áurea. Esta indicação foi aprovada, gerando protestos do Vereador Ricardo Gumblenton Daunt, que se manifestou contrário a ela. Os 
protestos do vereador não surtiram os efeitos desejados, mas o mesmo exigiu que se registrasse sua opinião sobre o ocorrido na sessão seguinte:

\begin{abstract}
Voto contra a indicação do Senhor José Paulino Nogueira para que a Câmara suspenda os trabalhos ordinários e regulares para se constituir em sessão extra para a extinção(sic) da Lei da Extinção da escravidão porque: $1^{\circ}$ entendo que a Câmara falta aos fins de sua instituição e a seus deveres em ouvir por qualquer motivo, não independente de sua vontade, de em dia de sessão ordinária se dedicar ao trabalho que seja de interesse de seus munícipes $2^{\circ}$ porque importando os festejos, nos quais a maioria da Câmara pretendia tomar parte, o celebrar-se o triunfo de uma parte da nação sobre a outra, convinha que quando a Câmara não simpatize com a causa vencida, ao menos se colocasse em posição de neutralidade absoluta não digo convindo por isso a sessão extra pedida na indicação.
\end{abstract}

Ou seja, o vereador entendeu que o papel da Câmara era trabalhar em prol dos cidadãos da cidade e que a questão da escravidão não estava dentro das prerrogativas da Casa, ao mesmo tempo em que realçou que a Lei Áurea não era consenso entre os cidadãos da cidade de Campinas e, portanto, não caberia manifestação da Casa a este respeito. A polêmica se estendeu quando o vereador

[...] Dr. Salvador Penteado apresentou a indicação seguinte: Para comemorar a gloriosa data da lei redentora que encheu de jubilo a população desta cidade e seu município Indico que a Rua de São José desta mesma cidade denomine-se Rua 13 de Maio [...].

Esta indicação provocou nova onda de protestos do vereador Ricardo Gumblenton Daunt, não sendo aprovada de imediato em virtude do requerimento de adiamento do vereador Sr. José de França. Os Srs. Otto Langaardt e A. Álvaro declararam que negaram seu apoio à proposta pelo propósito que tomaram de não mais mudar nomes de ruas. A mudança sugerida acabou sendo aprovada na sessão de 28 de maio de 1888 com a alteração do voto do Sr. Antônio Álvaro que assim explicou a mudança de sua opinião:

vota agora pela mudança do nome da Rua de São José por 13 de Maio e dá as razões porque assim procede. Atendendo que a data de 13 de Maio simboliza o mais importante feito nacional que é a extinção da escravidão; atendendo que esse glorioso feito é obra da soberania popular pois o que o governo fez foi somente a sanção da opinião pública; atendendo a estas considerações abre esta exceção e vota pela proposta.(18) 
O vereador justificou a alteração de uma conduta sua já consolidada, a saber: votar contra a mudança dos nomes das ruas, por entender que a abolição é obra da soberania popular e, dessa forma, tenta construir uma representação de que toda a cidade apóia a causa abolicionista, o que é contrário à avaliação do vereador Dr. Ricardo que afirma entender:

\footnotetext{
que tal mudança simboliza a vitória de um partido sobre o outro importa grave ofensa aos aderentes da causa vencida e contando-se entre estes além de outros muitos cidadãos a mas uma parte de indivíduos pertencentes as famílias territoriais, cuja influência social é por necessidade grande e a quem o município deve em máxima parte o seu estado de prosperidade e as instituições a que legitimamente se orgulha.
}

Assim, o Dr. Ricardo recolocou a questão, evidenciando que o que havia era uma disputa política entre os diversos segmentos representados na Câmara, e se aliou ao vereador Tenente Abreu, que justificou a seguinte proposta: que fosse mudado igualmente o nome da rua do rosário por "Regente D. Isabel", o que foi reprovado na mesma sessão após empate entre os vereadores e o desempate pelo voto qualificado do Vereador Otto Langardt, presidente da Câmara em exercício. (19) Aqui é preciso relembrar que o vereador Dr. Ricardo era o vice-presidente e que, em caso de ausência ou impedimento do presidente em exercício, o resultado da votação seria desfavorável ao grupo vencedor. Assim presenciamos uma vitória do grupo abolicionista no processo de construção de uma memória da cidade, que a representou como sendo abolicionista, muito embora haja uma correlação de forças através da qual se percebe que a sua vitória não foi tão exacerbada quanto hoje nos querem fazer crer.

Dentro da lógica da construção da representação da cidade moderna, a proclamação da república significa uma verdadeira transformação da nomenclatura das vias e logradouros da cidade; velhos símbolos da monarquia e da instituição religiosa cederam lugar aos novos símbolos republicanos e do positivismo dos militares republicanos, expresso na bandeira brasileira através do lema "Ordem e Progresso" e já marcados em Campinas desde a criação do Colégio Culto a Ciência. Os "conspiradores" republicanos passaram a ser grandes líderes que lutaram pelas 
idéias democráticas em defesa da liberdade, da igualdade e da fraternidade, enquanto a monarquia e a escravidão passaram a ser entendidas como um fardo do passado que é preciso esquecer, ou melhor, apagar.

Em sessão da Câmara de Vereadores de 25 de Novembro de 1889 aconteceu o seguinte debate:

Os srs. Drs. S. Penteado e A. Álvaro oferecerão a indicação seguinte que foi lida pelo primeiro. Considerando-se os grandes e importantes serviços prestados a causa da pátria e da liberdade pelos patriotas Major Sólon, (20) Dr. Benjamin Constant (21) e Marechal Deodoro, (22) indicamos que se dê a rua do Imperador o nome Marechal Deodoro, a rua do Caracol o de Benjamin Constant e a rua da Ponte o nome de Major Sólon. Antes sim que o Largo de S. Cruz se denomine d'hora em diante "Praça 15 de Novembro" em homenagem ao glorioso dia em que se fundou a Republica no Brasil. Considerando mais os importantes serviços que o nosso conterrâneo Francisco Glicério tem prestado a pátria pugnando sempre pelas liberdades públicas, e o papel saliente que tomou nos acontecimentos do dia 15 de Novembro, que se dê a rua do Rosário o nome de "Francisco Glicério", tanto mais quanto este ilustre cidadão nasceu nessa rua; a Câmara assim procedendo presta homenagem ao iminente patriota, filho da paragem desse serviço. Posta em discussão Dr. Ricardo fundamentou a seguinte emenda: Que a rua do Imperador se dê o nome Francisco Glicério e a do Rosário aquele de Marechal Deodoro. Continuando a indicação em discussão e posta a votos, salvo a emenda, foi ela integralmente aprovada, contra o voto do Dr. Ricardo na parte que se refere aos nomes de Major Sólon e Benjamin Constant, ficando prejudicada a emenda do mesmo vereador. (23)

Observemos que ser propagandista republicano com a proclamação da república passa a ser considerado pelos edis campineiros prestar "grandes e importantes serviços (...) a causa da pátria e da liberdade" o que representa uma adesão ao movimento vitorioso, mas, apenas após a vitória dos militares que proclamaram a república. Antes deste episódio, o grupo monarquista já havia inclusive tentado nomear uma das principais vias do município em homenagem à futura imperatriz do Brasil, como já foi destacado anteriormente e, nesse sentido, é preciso relembrar que a Princesa Isabel não foi considerada pelos mesmos edis como tendo prestado "os grandes e importantes serviços (...) a causa da pátria e da liberdade" quando assinou a Lei Áurea. O Imperador, por sua vez, homenageado desde a ocasião da sua visita em 1848, com a substituição do nome de Rua do Picador por Rua do 
Imperador, e mantida a homenagem em 1871 com a derrota do projeto do Dr. Ricardo para que a mesma retornasse ao nome original, agora já não é mais motivo de orgulho e nem digno de homenagem, mas sim, símbolo do atraso da pátria e de ausência de liberdade, sem que nenhum edil se levantasse em defesa da tradição, inclusive o próprio Dr. Ricardo.

O que teria motivado a alteração de postura dos vereadores no período em questão? Esta é uma pergunta em aberto, pode ser o temor da repressão militar, bem como também pode ser a perda de sustentabilidade política do Imperador junto aos antigos proprietários de escravos, mas isto é uma outra história. (24)

\section{Notas}

(1) "General Carneiro: Antônio Ernesto Gomes Carneiro nasceu na cidade de Serro em Minas Gerais a 19 de novembro de 1846. Seu pai era farmacêutico e este deveria seguir a mesma profissão. Contudo durante a Guerra do Paraguai alistou-se entre os Voluntários da Pátria. Terminada a Guerra ingressou na Escola Militar e em seguida na Escola de Tiro de Campo Grande. Era republicano por convicção. No entanto um de seus filhos sofreu um acidente e teve as pernas decepadas. O Imperador Pedro II, além de lhe fazer uma visita cordial, providenciou para o menino o primeiro aparelho ortopédico usado no Brasil, o que possibilitou que este voltasse a andar. Para mostrar sua gratidão Gomes Carneiro afastou-se de seus colegas republicanos. Criou na cidade do Rio de Janeiro, um Colégio Militar para os filhos órfãos dos combatentes da Guerra do Paraguai, assim como para os demais veteranos da Guerra. Já na República, durante a crise que levou à renúncia de Deodoro da Fonseca, foi auxiliar de Floriano Peixoto. Com o início da Revolução Federalista (1893) foi mandado por Floriano para defender o Paraná. Organizou a resistência na cidade da Lapa, onde morreu no dia 09 de fevereiro de 1894, durante um violento combate." Referências biográficas do General Carneiro obtidas em EL KHATIB, Faissak. História do Paraná. Curitiba: Grafipar, 1969. [Acervo Casa da Memória Paraná].

(2) Processo semelhante ocorreu na cidade de São Paulo como descrito por Laura Antunes Maciel em relação à Praça da República. MACIEL, Laura Antunes. Uma praça para a República. In: REIS, Maria Cândida Delgado. Caetano de Campos: fragmentos para a História da Instrução Pública no Estado de São Paulo. São Paulo, SP: Associação de EX-Alunos do Instituto de Educação Caetano de Campos, 1994. p. 21-30.

(3) Ver Código de Posturas de 1880, citado em José Roberto do Amaral Lapa: A cidade: o canto e os antros Campinas 1850-1900, São Paulo, Edusp, 1996, p. 48.

(4) Dados utilizados na confecção das duas tabelas foram extraídos das obras Retratos da velha Campinas, de Geraldo Sesso Júnior; Campinas, ruas do Império, de Edmo Goulart; e A cidade: o canto e os antros - Campinas 1850-1900, de José Roberto do Amaral Lapa.

(5) Na definição de período republicano estamos incorporando o período de surgimento e fortalecimento do P.R.P., bem como o momento pós proclamação da Republica.

(6) Arquivo da Câmara Municipal de Campinas. Livro de Leis e Resoluções relativas aos annos de 1890-1892 publicadas pela Intendência Municipal de Campinas, página 25 do ano de 1892.

(7) Respectivamente a data e o principal sujeito da proclamação da República.

(8) Arquivo da Câmara Municipal de Campinas. Livro de Leis e Resoluções relativas aos annos de 1901 a 1910 da Mesa da Câmara Municipal de Campinas, publicadas pela Intendência Municipal de Campinas, página 04 do ano de 1902. 
(9) Ata da Sessão Ordinária em 3 de julho de 1871, Livro 149 de Atas da Câmara Municipal de Campinas, folha 61.

(10) Ata da Sessão Ordinária em 11 de dezembro de 1871, Livro 149 de Atas da Câmara Municipal de Campinas, folha 97.

(11) Arquivo do Setor de Nomenclaturas, Secretaria Municipal de Planejamento Urbano e Meio Ambiente.

(12) Joaquim Saldanha Marinho nasceu a 4 de maio de 1816, em Olinda, Pernambuco, e morreu a 28 de maio de 1895, no Rio de Janeiro. Político Brasileiro. Deputado e Senador. Promotor Público, secretário de governo e presidente do Instituto dos Advogados Brasileiros. Formou-se em 1836 pela Faculdade de Direito de Olinda. Foi promotor público e secretário de governo. Elege-se deputado provincial e, depois, geral, pelo Ceará. Em 1860, transfere-se para o Rio de Janeiro, onde se dedica ao jornalismo. Em 1861, elege-se deputado geral, desta vez pelo Rio de Janeiro, reelegendo-se até 1867, quando se elege por Pernambuco. De 1865 a 1867 presidiu a Província de Minas Gerais e, de1867 a 1868, a de São Paulo. Em 1878, elege-se deputado geral pelo Amazonas. Proclamada a República, elege-se senador constituinte pelo Distrito federal e participa da primeira legislatura ordinária do Congresso Nacional, de 1891 a 1893. Foi também presidente do Instituto dos Advogados Brasileiros. Sob o pseudônimo de Ganganelli, escreveu, no Jornal do Comércio, vários artigos sobre a questão religiosa suscitada pelos bispos do Pará e de Olinda, reunidos posteriormente no livro A lgreja e o Estado (1873 a 1876, 4 volumes).

(13) Álvares Machado, nasceu em São Paulo, no dia 21 de Dezembro de 1791, era cirurgião de profissão. Em Itu, praticou e se aperfeiçoou na profissão acompanhando o pai onde passou pelo "proto-medicato" e veio a estabelecer-se na Vila de São Carlos, atual Campinas. Na política foi um grande orador, tendo sido acolhido pelos liberais. Pugnou pela independência brasileira, pela permanência de Pedro I no Brasil, porém pouco tempo depois defendeu a abdicação do Imperador e influenciou na Província de São Paulo para a aceitação da maioridade do Imperador. Durante a Revolta dos Farrapos aceitou a presidência da Província Rio Grandense, tendo fracassado na tentativa de pacificação dos revoltosos. Faleceu em Niterói em 1846. Para maiores informações ver Francisco José Monteiro Salles, Joaquim Correa de Mello, sua vida e sua obra, publicação da Academia Campinense de Letras, Campinas, SP, n. 38, p. 7-10, 1978.

(14) José Maria da Silva Paranhos, Visconde do Rio Branco, nasceu a 16 de março de 1819, em Salvador, Bahia, e morreu a 1 de novembro de 1880, no Rio de Janeiro. Estadista, jornalista, diplomata e parlamentar brasileiro. Professor da Escola Militar. Ministro da marinha e, depois, da Fazenda, da Guerra e dos Estrangeiros. Presidente da Província do Rio de Janeiro. Senador vitalício.

Em 1841, ingressou na Escola Militar, egresso da Academia da Marinha. Foi redator do jornal Novo tempo. Deputado pelo Rio de Janeiro em 1848, foi secretário do Visconde do Paraná e ministro residente em Montevidéu. Durante o Ministério de Conciliação ocupou a Pasta da Marinha. Em 1857, foi ministro da Fazenda, e no ano seguinte assumiu a presidência da província do Rio de Janeiro, cargo em que teve curta passagem, pois logo veio a acumular as Pastas da Guerra e dos Estrangeiros. No gabinete de Caxias, voltou a ocupar o Ministério da Fazenda. Representou, em 1862, o Mato Grosso no Senado Vitalício. No ano seguinte, passa a conselheiro de Estado. Novamente ministro dos Estrangeiros no gabinete Itaboraí, é elevado a visconde em 1870. Chefiando o ministério de 1871 a 1875, promulgou a reforma judiciária e apresentou a Lei do Ventre Livre, que passou a ter o seu nome. Promoveu o primeiro recenseamento do Império. Dirigiu a Escola Politécnica e construiu a Estrada de Ferro D. Pedro II (atual Central do Brasil).

(15) Ata da Sessão Ordinária em 11 de dezembro de 1871, Livro 149 de Atas da Câmara Municipal de Campinas, folha 97 .

(16) O nome da atual Rua 11 de agosto é uma homenagem ao dia da chegada da Locomotiva da Cia. Paulista de Estradas de Ferro em substituição ao nome de Rua do Campo.

(17) Ata da Sessão Ordinária em 16 de maio de 1888, Livro 156 de Atas da Câmara Municipal de Campinas, folhas 38 verso e 39 .

(18) Ata da Sessão Ordinária em 16 de maio de 1888, Livro 156 de Atas da Câmara Municipal de Campinas, folha 40 verso.

(19) Ata da Sessão Ordinária em 28 de maio de 1888, Livro 156 de Atas da Câmara Municipal de Campinas, folhas 41 verso e 42.

(20) Frederico Sólon Sampaio Ribeiro nasceu no ano de 1842, em Porto Alegre, Rio Grande do Sul, e morreu no ano de 1900, no Rio de Janeiro. Militar brasileiro. Participou do grupo que conspirou contra a monarquia brasileira proclamando a República a 15 de novembro de 1889. Logo cedo entrou para a escola militar da corte onde completou o curso de infantaria e cavalaria. Participou das campanhas contra Rosas e Aguirre tendo-se destacado na batalha de Paissandu e no cerco de Montevidéu. Conta-se que teria sido ele que precipitou a proclamação da República já que estava marcada para o dia 20 de novembro e não dia 15, espalhando o boato 
de que Deodoro, Benjamin e Mena Barreto já estavam presos. Também foi ele quem levou a mensagem para $D$. Pedro II de que deveria abandonar o país juntamente com a família real. Durante o governo provisório, recusou a pasta da Guerra, alegando que preferia continuar engajado no Exército para garantir a permanência da República. Foi ainda deputado federal pelo Estado do Mato Grosso e comandante do distrito militar e inspetor do Arsenal de Guerra do Pará.

(21) Benjamin Constant Botelho de Magalhães nasceu em Niterói (bairro de São Lourenço), Rio de Janeiro, a 18 de outubro de 1836, e morreu no Rio de Janeiro, a 22 de janeiro de 1891. Militar, professor e estadista brasileiro, um dos principais articuladores da República e autor da legenda Ordem e Progresso, da bandeira brasileira.

Órfão de pai aos 13 anos, assumiu a responsabilidade de cuidar da família. Dedicava-se aos estudos e encontrava tempo para dar aulas particulares. Alistou-se no Exército em 1852 e um ano depois ingressou na Escola Militar. O magistério, entretanto, exercia sobre ele maior fascínio. Lecionou na própria Escola Militar, na Escola Normal e na Politécnica, lutando ardorosamente pelo desenvolvimento do ensino no Brasil. Fundou o Instituto dos Meninos Cegos, que hoje ostenta seu nome, dirigindo-o durante longo período. Permaneceu 13 anos no posto de major, sendo promovido a tenente-coronel a 30 de maio de 1888. Participou da Guerra do Paraguai integrando a Comissão de Engenheiros, em Tuiuti e Tuiu-Cuê, abrindo trincheiras, construindo pontes e elaborando roteiros. Regressou à caserna a 4 de outubro de $1867 \mathrm{com}$ a saúde profundamente abalada. Líder dos movimentos republicanos, lutou ferrenhamente pela causa, enfrentando com altivez o Visconde de Ouro Preto. Na Questão Militar de 1887, Benjamin soube defender seus companheiros de farda, insultados pelo governo. È considerado oficialmente o fundador da República. Segundo Costa Rego, "Benjamin Constant não conspirou. Professou...Não tinha cúmplices, tinha discípulos." Afirma, ainda, Costa Rego: "Benjamin não preparou rebelados. Levantou consciências." Proclamada a República ele assumiu a Pasta da Guerra do gabinete revolucionário, permanecendo no cargo até 30 de abril de 1890. Nessa mesma data, passou a ocupar o Ministério da Instrução Pública, Correios e Telégrafos, elevado ao posto de general-de-brigada. É de sua autoria a inscrição Ordem e Progresso inserida na bandeira nacional. Benjamin Constant exerceu, também, o cargo de astrônomo-ajudante do Observatório do Rio de Janeiro.

(22) Manuel Deodoro da Fonseca nasceu em Alagoas, a 5 de agosto de 1827, e morreu no Rio de Janeiro , a 23 de agosto de 1892. Militar, proclamador da República do Brasil e o primeiro presidente no governo provisório e posteriormente no constitucional. Cursou a Escola Militar do Rio de Janeiro; a partir de 1843 alcançou o posto de tenente. Transferido para Pernambuco (1849) teve atuação destacada ao sufocar a rebelião denominada Praieira. Assumiu as funções de ajudante do $1^{\circ}$ Batalhão de Engenheiros formado no dia 1 de abril de 1855. Capitão (1864) do $1^{\circ}$ Batalhão de Artilharia, Deodoro participou das campanhas do Uruguai (invasão do Rio Grande do Sul pelos "blancos"), entrando vitorioso em Montevidéu a 20 de fevereiro de 1865. Em seguida partiu para a província Entre-Rios e passou a lutar na Guerra do Paraguai, quando foi ligeiramente ferido na Batalha de Itororó. Promovido sucessivamente a major, tenente-coronel e coronel, deixou o Paraguai a 14 de julho de 1870 , quando restabelecida a ordem. Brigadeiro em 1874 e marechal-de-campo (1884), tomou posse no cargo de comandante das Armas do Rio Grande do Sul, em 1885. Apoiando seus companheiros de farda, num atrito entre eles e o Parlamento, Deodoro, altivamente, recusou um título honorífico e uma ajuda de custo. Por essa atitude foi exonerado das funções que exercia. Seu prestígio cresceu dentro do Exército, preocupando os políticos. Daí sua nomeação para comandante das armas de Mato Grosso para afastá-lo, sobretudo, do Rio de Janeiro. A essa altura os movimentos republicanos ganhavam corpo e Deodoro, constantemente assediado por Benjamin, Quintino e outros, acabou aderindo ao movimento no dia 10 de novembro de 1889. Proclamada a República, Deodoro assumiu a chefia do governo provisório. Promulgada a primeira Constituição da República, a 24 de fevereiro de 1891, já no dia seguinte o Congresso Constituinte elegeu Deodoro presidente da República, cujo mandato deveria terminar em 1894. Aborrecido com a atuação dos parlamentares e entendendo que vinham interferindo nos problemas afetos ao chefe da Nação, Deodoro dissolveu o Congresso no dia 3 de novembro de 1891. Vinte dias depois eclodiu no Rio de Janeiro a revolta da Armada, sob o comando do contra-almirante Custódio de Melo. Antevendo uma guerra civil de proporções alarmantes, Deodoro renunciou ao mandato e entregou o governo ao vice-presidente Marechal Floriano Peixoto. Acabou morrendo alguns meses depois.

(23) Ata da Sessão Ordinária em 25 de novembro de 1889, Livro 157 de Atas da Câmara Municipal de Campinas, folhas 30 verso e 31 .

(24) Para maiores informações ver Campos Porto, M. E. de, Apontamentos para a História da República dos Estados Unidos do Brasil, Rio de Janeiro, Imprensa Nacional, 1890. Nesta obra o autor relata ironicamente uma doença que assaltava os diferentes segmentos da sociedade brasileira, que adormecera monarquista e despertara, no 15 de novembro de 1889, republicana convicta.

\section{Referências Bibliográficas}

AMARAL, Leopoldo. Campinas: recordações. São Paulo: Secção de Obras do Estado de São Paulo, 1927.

BARRETTO, Margarita. Vivendo a história de Campinas. Campinas: Mercado de Letras, 1995. 
BATISTONI, Duílio. Campinas: uma visão histórica. Campinas: Pontes, 1996.

BRITO, Jolumá. História da cidade de Campinas: [s.n.], 1956.

CAMPINAS em Ferro e Bronze. Catálogo editado pela Prefeitura Municipal de Campinas por ocasião do Bicentenário, em 1974.

CAMPOS PORTO, Manuel Ernesto de. Apontamentos para a História da República dos Estados Unidos do Brasil. Rio de Janeiro: Imprensa Nacional, 1890.

CARPINTERO, Antonio Carlos Cabral. Momento de ruptura: as transformações no centro de Campinas na década dos cinqüenta. Campinas: CMU / Unicamp, 1996.

DAUNT NETO, Ricardo Gumbleton. Ricardo Gumbleton DAUNT. in Monografia Histórica do Município de Campinas: Câmara Municipal de Campinas. Rio de Janeiro: Instituto Brasileiro de Geografia e Estatística, 1952. p. 289-296.

EL KHATIB, Faissak. História do Paraná. Curitiba: Grafipar, 1969. [Acervo Casa da Memória Paraná].

GOULART, Edmo. Campinas: ruas da época imperial. Campinas: Maranata, 1983.

GUIDUCCI, Roberto. A cidade dos cidadãos: um urbanismo para todos. Tradução de Patrícia M. E. Cenachi. São Paulo: Brasiliense, 1980.

GUIMARÃES, Alaor Malta. Campinas: dados históricos e estatísticos. Campinas: Livraria Brasil, 1953. Contém um guia completo de ruas.

LAPA, José Roberto do Amaral. A cidade: o canto e os antros - Campinas 1850-1900. São Paulo: Edusp, 1996.

MARIANO, Julio. Campinas de ontem e anteontem. Campinas: Maranata, 1970.

MENEZES, Raimundo de. Vida e obra de Campos Salles. São Paulo: Resenha Tributária, 1974.

MONOGRAFIA Histórica do Município de Campinas: Câmara Municipal de Campinas. Rio de Janeiro: Instituto Brasileiro de Geografia e Estatística, 1952.

MONTEIRO, Ana Maria Reis de Góes. Ramos de Azevedo e seu Projeto de Posturas para uma Nova Campinas. Oculum Ensaios: Revista de Arquitetura e Urbanismo (FAU - PCCAMP), Campinas, n. 2, p. 24-43, 2002.

PUPO, Benedito Barbosa. À margem da história de Campinas: as origens da cidade e oficialização da data de sua fundação. 2. ed. Campinas: Tipografia Matos, 1976.

SALLES, Francisco José Monteiro. Joaquim Correa de Mello: sua vida e sua obra. Academia Campinense de Letras, Campinas, SP, n. 38, p. 7-10, 1978.

SANTOS, Antonio da Costa. Campinas, das origens ao futuro: compra e venda de terra e água e um tombamento na primeira sesmaria da Freguesia de Nossa Senhora da Conceição das Campinas do Mato Grosso de Jundiaí (1732-1992). Campinas, SP: Editora da Unicamp, 2002. 400 p.

SESSO JÚNIOR, Geraldo. Retalhos da velha Campinas. Campinas: Palmeiras, 1970.

* Bacharel e licenciado em História pelo Departamento de História, do Instituto de Filosofia e Ciências Humanas, da Universidade Estadual de Campinas e Historiador do Museu da Cidade da Prefeitura Municipal de Campinas.

e-mail: abvillela@pop.com.br 